\title{
The Cultivation of Employment Competitiveness of Students Majoring in Elementary Education
}

\author{
Lei WANG \\ Linyi University, Feixian Campus, Feixian, Shandong, China \\ Email:lyulgc@126.com
}

Keywords: Elementary education major, Employment competitiveness, Training countermeasures.

\begin{abstract}
The problem of college students' employment is a center strategic one among employment problems in China. As for cultivating the employment competitiveness of students, there are problems like the biased cultivating objectives, outdated curriculum and teaching methods, the disorderly extracurricular activities, in elementary education major, which is a new major in high normal university. The paper take the case of Linyi university, Feixian (F college) and makes an analysis of the causes of these problems and gives solutions to them.
\end{abstract}

\section{Introduction}

Employment is the root of people's livelihood, the problem of college students' employment is a center strategic one among employment problems in China. The elementary education course is a newborn major in high normal school, also is influenced by the traditional educational system and the cultivating model. All the above leads to the inferior position of students graduated from the major with weak employment competitiveness in fierce market competition. To achieve superiority in job-hunting, great importance must be attached to the cultivation of employment competitiveness of students majoring in elementary education.

\section{Problems Exist in College in Cultivating Employment competitiveness of Students}

The employment competitiveness of students majoring in elementary education is linked closely with school education. The main problems exists in the cultivation of employment competitiveness of students majoring in elementary education are as follows: the biased cultivating objectives, outdated curriculum and teaching methods, the disorderly extracurricular activities.

\section{The Biased Cultivating Objectives}

Under the guidance of educational aim of the nation, the cultivating objectives makes concrete request to the direction, the content and the standard of students' development. Apart from being the weathervane of talent-cultivation project in college, the raise goal is also the starting point and aim of all the educational activities. Without scientific and clear cultivating objectives, the talent- cultivation project in college will get lost. Being a local normal college, $F$ college developed from a secondary normal school. In talent-cultivating project, it can't define and express itself accurately and practically, as a result, not only the role of the cultivating objectives of the elementary education in F college can't be given full play to, but also the enhancement of training quality of students majoring in elementary education will be limited. According to the survey, students identify the "biased cultivating 
objectives "[1] as chief culprit of their weak employment competitiveness. After comprehensive analysis, I think the deviation manifested chiefly by mistaking versatile specialist as expert-like talents; besides, students lack the flexibility and failed to keep up to date during job-hunting; furthermore, so far, the main question is that " qualified elementary school teachers" and "applied talents" are what we really need on elementary education, which have been ignored.

\section{The Outdated Curriculum and Teaching Methods}

Teaching activity is a kind of indirect cognitive activity. In teaching activities, students are required to master the course and teaching materials. And, the course is not only the main source of students' acquisition of knowledge, but also their learning instructions. Teaching activities is still the primary one among varieties of channels in college for students to acquire knowledge. Problems like outdated course installation and teaching activities still exist in F college.

\section{The Disorderly Extracurricular Activities}

Different from classroom education, the extracurricular activity, as a teaching method, has its own features. It plays an important role in promoting students' growth and means a lot to their development[2]. The extracurricular activity will help to deepen and firm the classroom knowledge, through integrating indirect knowledge with practice, it will help to deepen students' understanding, and furthermore generate new knowledge and skills. Enrich the contents and forms of extracurricular activity will not only help to inspire students to be more full of creative power and cultivate their handling ability, but also will help to promoting their ability of social communication. Students can touch the rich but complex society through extracurricular activities, they will learn how to communicate with people, how to get acquaintance and judge others. All the above will make preparations for students to know, to get into society and to adapt to it. 88.4 percent of respondents ascribe the weak employment competitiveness of students majored in elementary education to the lack of extracurricular activities. Problems are as follows: school hasn't put enough emphasis on extracurricular activities, the activities school has arranged hasn't take the students of different majors and personalities into account; besides, the instructions from professional teachers is rather limited.

\section{The Reasons of Problems}

To solve the existing questions in cultivating employment competitiveness of students majoring in elementary education, we need to analyze the reasons scientifically so as to take appropriate measures.

\section{The Lack of Clear Cognition on the Employment Competitiveness of Students Majoring in Elementary Education}

Firstly, enough emphasis hasn't been attached to the importance of the employment competitiveness of students majoring in elementary education. On one hand, as for the school, it hasn't put enough emphasis on the importance of the employment competitiveness of students; besides, it hasn't take appropriate systematic and appraising measures on the cultivation of the employment competitiveness. On the other hand, as for the teachers, they tend to think the cultivation of the employment competitiveness of students is the duty of Administrative Department and Department of Labor of school[3]. With such narrow-minded views, naturally, teachers will ignore the cultivation of the employment competitiveness of students in teaching, and 
certainly they will not pay attention to arrange the correspondent curriculum or enhancing their teaching methods.

Secondly, enough emphasis hasn't been attached to the importance of the components of the employment competitiveness of students majoring in elementary education. First of all, the specialized knowledge has been mistaken for skills. Specialized knowledge means that people will get to know or understand something new through courses of study, while the skills is that people can do something new through course.

Furthermore, students tend to overemphasize the role of varieties of certificate they have attained. School time is precious but limited, if students focus too much on obtaining varieties of certificates blindly, naturally they will neglect the improvement of their skills. Besides, students tend to mistaken what they have undergone for experience. The employers are increasingly emphasize the practical experiences of college students, so during on campus, college students are encouraged to take part in social practice. But, it should be noted that what you have undergone does not equal experiences.

\section{Rigid School-running Modes is Rather Slow to React to the Employment Market}

So far, the local characteristics of normal major in many local normal colleges is not distinct enough, both the educational theory and the practical skills are not well enough to meet the requirement of training a qualified elementary teacher. As for the curriculum, too much compulsory courses are set, being a system, the integrality and the logicality of the discipline are overemphasized[4]. The content of courses is vague and general, divorced from the reality, barely considered what kind of elementary teacher do we really need. Courses like "Instruction of Employment and Enterprising" hasn't set, even some school has open the class, the class time is still insufficient. The major that school has set cannot meet the demand of the employment market, school hasn't take students' employment into account, fails to be geared with the social demand.

The rigid educational ideas and cultivating patterns lead to the weak employment competitiveness. In many local normal colleges, both the teachers and the leadership paid no attention to the quality of education, to the employment-oriented concept, and neglected the market sense, competitive sense. They insist on regarding the discipline teaching as the standard, put much more attention on disciplinary base and profession, students are adapting to the school teaching passively. The School still adopted theory-teaching based teaching model, with the support of the practical teaching. In such circumstances, students get little access to take part in social practices, or even get the chance, the contents of the practice is rather simple and dull[5].

Teachers lack sufficient knowledge on the job market. During teacher's management, the lack of the theory of survival of the fittest resulted in the lack of stress of tough competition and the motivation to innovate. They tend to focus more on textbooks than the market, more on theory than the real society, naturally, they will not pay close attention to the development of social economy, or spend much time in studying the change of the demand in labor market.

\section{The Mutual Complementary and Cooperation of the Extracurricular Activity is Insufficient}

The leadership of college lack appropriate recognition on the value of the extracurricular activities, while this, resulted in the existence of disorderly extracurricular activities. Many college do not have scientific planning or institutional 
guarantee when carrying out extracurricular activities, they just let it take care of itself. The old teaching conception should be enriched with new contents and materials that can motivate innovations, rather than always the same old one. The teaching plan hasn't take planned extracurricular activities into account, as a result, the organic integration of extracurricular activities and theory in the textbooks fails to achieve, the actual effect of the innovative education. Without the exploration of constructing innovation education teaching model, the extracurricular activities will not bring multiplier effect.

\section{Measures to Promote the Employment Competitiveness}

\section{Strengthen the Study on Employment Competitiveness of College Students}

Fully recognize the value of employment competitiveness of college students. The development of social economy requires more qualities from the human resource, while the market allocation of human resource will surely arouse intense competition among them. Meanwhile, the college will continue to advance the enrollment expansion, the number of college graduates keeps increasing year by year, so, the employment pressure is rising the same. Especially for local college students, the situations they face is much more serious. Therefore, we should fully recognize the importance of strengthening the employment competitiveness of college students, students themselves should enhance the competitive ability, so as to highlight their advantages in talent market.

Fully understand the content of employment competitiveness of college students. Different from other common abilities, the employment competitiveness has its own characteristics like uniqueness, value, dynamic and internalization[6]. It doesn't equal to specific skills. As for students majored in elementary education, skills like calligraphy or piano is an important component of employment competitiveness, however, such skills will not guarantee students' success in employment market, even if they make it through skills, they still cannot maintain the advantages for long during their work. The employment competitiveness is much more a combination of various comprehensive abilities than specific skills. Analyze the component of employment competitiveness of elementary education scientifically. Based on the employment competitiveness of college students, the employment competitiveness of elementary education make certain extensions and take the vocational and professional characteristics into account, it concludes not only the basic competitiveness college students should have, but also the core competence adapted to the teaching profession.

\section{Strengthen the Links with Employment Market}

Make correct judgment on the quality standards of the talents demanded from market. The employers' demand for talents, both on the professional needs and capacity quality, are changing, overall, the skilled, compound and innovative talents are much more popular. The employers value more on the comprehensive quality, the interpersonal communication ability, teamwork capacity, the capacity for innovation, the entrepreneurship and the practical competence of students.

Construct the verify platform on training mode of talents for employment market, and the dynamic feedback mechanism of information on the employment market[7]. Focus on the demand for talents from employment market, adjust the cultivating objectives of the elementary education major in time, so as to make it conform to the employment market. Build a platform for free information and communication, better 
the dynamic feedback mechanism of information on the employment market.

\section{Build the Curricular and Teaching System Based on Employment Competitiveness}

Curriculum is the key part of talent training, the school curriculum should keep up with social development, and be foresighted. Such curriculum will promote students to put their theoretical knowledge into practical use. To avoid problems like the unreasonable structure and repeated teaching contents in curriculum, when arranging courses, the policy maker should take the special requirement and the social adaptability into account. Practical and applied courses should be added to cultivate students' hands-on ability. The teaching contents should take in account the structure of the curriculum itself, while not neglect the academic front knowledge and latest research on professional area.

\section{Using "Integration of In-and -On Class" Education}

Based on the need of educates and educational teaching, extracurricular activities aimed to supplement the classroom teaching ,to achieve the educational objective under the direct or indirect guidance of school organizations or out-of-school educational institutions.

\section{Conclusions}

As for normal colleges, they should organize guided activities that will benefit students' job-hunting, and establish the running mode of employment of our school and integration platform, which concludes organization and management, the construction of employment system, the construction of career guidance staff, the construction of system of career guidance curriculum. Apart from strengthening class teaching's role of being chief position, school should encourage students to carry out extracurricular activities actively, open up "social classroom", help students to put the knowledge they have learned in textbooks into practical use, so as to motivate students' enthusiasm for learning. The elementary education course is a newborn major in high normal school systems, and it has been advancing under the influence of the traditional educational system and the cultivating model. The employment competitiveness of students is an important breakthrough of the professional development. The cultivation of the employment competitiveness of students majoring in elementary education is imperative.

\section{Acknowledgment}

The author wishes to express his sincere thanks to the editor and the anonymous referees for their valuable suggestions and helpful comments which could improve the presentation of the paper.

\section{References}

[1] Yao Dechao, Yan Yueping, The Construction of System of Students' Core Employment Competitiveness [J].Educational Review,2009 (1).

[2] Ji Hongyi, Mao Zhiyong, Thoughts about Promoting the Employment Competitiveness of Applied College Graduates [M]. Education and Vocation, 2010

[3] Fu Zhentong, The Study of Core Competence of High Normal Colleges 
[D].Changchun: Jilin University,2008.

[4] Liu Cunsheng, Xu Changfa, Vocational Education [M].Beijing:Educational Science Publishing House,2002: pp.89-90.

[5] Ying Songbao, The Interactions between the College Students' Labor Market Segmentation and the Higher Education [J].China Higher Education Research,2007

[6] Sun Wandong, Liang Shuyan, Measures to Enhance the Employment Competitiveness of Normal College Graduates [J].Heilongjiang Researches on Higher Education, 2007, (9).

[7] Zhou Ying, The Study on Core Employment Competitiveness of Higher Vocational Graduates [D].Nanjing:Southeast University, 2009. 